\title{
Knowledge, Perceptions, and Attitude of Egyptians Towards the Novel Coronavirus Disease (COVID-19)
}

\author{
Ahmed Samir Abdelhafiz ${ }^{1} \cdot$ Zeinab Mohammed ${ }^{2} \cdot$ Maha Emad Ibrahim $^{3} \cdot$ Hany H. Ziady ${ }^{4} \cdot$ Mohamed Alorabi $^{5}$. \\ Mohamed Ayyad ${ }^{6}$ Eman A. Sultan ${ }^{4}$
}

Published online: 21 April 2020

○) Springer Science+Business Media, LLC, part of Springer Nature 2020

\begin{abstract}
Coronavirus disease 2019 (COVID-19) has been recognized as a pandemic by the World Health Organization. Global efforts have been exerted to prevent the spreading of the disease through political decisions together with personal behaviors, which depend on awareness of the public. The goal of this study is to assess the knowledge, perceptions and attitude of the Egyptian public towards the COVID-19 disease. We conducted a cross-sectional survey about these points, which was distributed among adult Egyptians. Five hundred and fifty nine persons completed the survey. The mean knowledge score was 16.39 out of 23, gained mainly though social media (66.9\%), and the internet (58.3\%). Knowledge was significantly lower among older, less educated, lower income participants, and rural residents. Most participants (86.9\%) were concerned about the risk of infection. While $37.6 \%$ thought that their salary will be continued if they become isolated, $68.5 \%$ believed that it should be continued during this period. About $73.0 \%$ were looking forward to get the vaccine when available. In general, participants had a good knowledge about the disease and a positive attitude towards protective measures. This knowledge is gained mainly through novel media channels, which have pros and cons. Although the government has taken major steps to educate the public and limit the spread of the disease, more effort is needed to educate and support the lower economic strata. If a vaccine or a treatment is approved, we recommend a government control over its use to preserve the rights of the vulnerable and needy groups.
\end{abstract}

Keywords COVID-19 $\cdot$ Egypt $\cdot$ Knowledge $\cdot$ Perceptions $\cdot$ Attitude

Electronic supplementary material The online version of this article (https://doi.org/10.1007/s10900-020-00827-7) contains supplementary material, which is available to authorized users.

Ahmed Samir Abdelhafiz

ahmed.samir@nci.cu.edu.eg

1 Department of Clinical Pathology, National Cancer Institute, Cairo University, Kasr Al-Aini Street, Fom Elkhalig Square, Cairo 11796, Egypt

2 Department of Public Health and Community Medicine, Faculty of Medicine, Beni-Suef University, Beni-Suef, Egypt

3 Department of Physical Medicine, Rheumatology and Rehabilitation, Faculty of Medicine, Suez Canal University, Ismailia, Egypt

4 Department of Community Medicine, Faculty of Medicine, Alexandria University, Alexandria, Egypt

5 Department of Clinical Oncology, Faculty of Medicine, Ain Shams University, Cairo, Egypt

6 Department of Surgical Oncology, National Cancer Institute, Cairo University, Cairo, Egypt

\section{Introduction}

In December 2019, a rapidly infectious disease emerged in Wuhan city in China. The disease was caused by a member of the family of coronaviruses, finally named severe acute respiratory syndrome coronavirus 2 (SARS-CoV-2). The highly contagious virus, which caused the disease called coronavirus disease (COVID-19), spread outside China and has since become a global public health emergency [1]. In severe cases, the virus causes fatal pneumonia similar to that caused by severe acute respiratory syndrome coronavirus (SARS-CoV), and Middle East respiratory syndrome coronavirus (MERS-CoV), which have emerged in the past 20 years in sporadic countries all over the world [2].

The coronaviruses have become the major pathogens of emerging respiratory disease outbreaks. They represent a large family of single-stranded RNA viruses, which can cause illness ranging from a common cold to severe symptoms like MERS and SARS [3]. The clinical symptoms 
of COVID-19 include fever, which is the most common symptom, cough, fatigue, malaise, and shortness of breath. Global concerns about the virus have risen due to its high transmission capability, which may be coupled with morbidity and mortality [4]. The elderly and patients with comorbidities are more likely to be infected and are additionally more prone to serious complications, which may be associated with acute respiratory distress syndrome (ARDS) and cytokine storm [5].

Till the moment, there is no proved treatment or vaccination against SARS-CoV-2. Strong infection control measures are the primary intervention to minimize the spread of the virus in both health care settings and the community [6]. Public awareness of dealing with highly infectious respiratory diseases plays a vital role in limiting the spread of the infection, especially in middle and low-income countries, where health systems have, at best, the moderate capacity to respond to outbreaks. In Egypt, by the beginning of April of 2020, there were over 800 confirmed cases, with more than 50 fatalities, and a rapid tendency towards increase [7]. Vaccine development is estimated to require months, and thus management of the crisis depends primarily on people's adherence to the recommended measures taken. These measures are largely affected by knowledge, attitudes, and practices (KAP) of the public [8].

In China, lessons learned from the SARS outbreak in 2003 suggest that knowledge and attitudes towards infectious diseases are associated with the level of panic emotion among the population, which can further complicate attempts to prevent the spread of the disease [9]. Behaviors like underestimation, stigmatization, panic emotions, false measures to avoid infection affect the battle against such an uncommon situation [8]. This work aims to assess knowledge, attitudes and perceptions about COVID-19 among a convenience sample of the general public in Egypt.

\section{Subjects and Methods}

\section{Study Design and Population}

A cross-sectional survey was designed for the present study. The study was conducted in March 2020 among Egyptian adults, who are not working in the medical field. The survey was conducted through a link shared on social networking sites as well as through personal interviews. The latter was limited to limit the spread of the disease.

\section{Study Tool}

The survey questionnaire was designed in Arabic, the native language in Egypt, and it covered the socio-demographic characteristics, knowledge regarding COVID-19, perceptions about the disease, and attitude towards protective measures against COVID-19.

\section{Validation and Pilot Study}

A preliminary phase was conducted to assess the validity and reliability of the questionnaire before its use. Initially, three Egyptian experts in the field of epidemiology and research in Egyptian universities were asked to assess the degree to which items in the questionnaires are relevant and can correctly measure knowledge and attitude of the Egyptian public regarding COVID-19. Afterwards, questions inquiring about the attitude towards preventive measures were modified to reflect the attitude and not actual practice.

The next step was pretesting of the questionnaire on 20 participants who were excluded later from the study sample. They were asked to fill the questionnaire twice 2 weeks apart. Data were used to assess internal consistency reliability using cronbach's alpha as well as test-retest reliability using the intra-class correlation coefficient. The results showed adequate internal consistency reliability (with cronbach's alpha $=0.72$ and the intra-class correlation coefficient was 0.96 ).

\section{Data Collection}

An online survey portal, Google Form was created, and participants were invited to complete and submit the form. A number of surveys were also collected through personal interviews, where data collectors interviewed patients at university hospitals. The process of calling participants to share in the survey was conducted through convenient sampling. It started from four starting points simultaneously (Cairo, Alexandria, Beni-Suef and Suez Canal) which roughly represent the main regions in Egypt, i.e. Central (Cairo), North (Alexandria), Upper Egypt or South (Beni-Suef), and East (Suez Canal). From these four starting points, participants continued to spread and were expected to cover most of the governorates in the country.

\section{Sampling}

The sample size was determined using the Epi Info 7 software. As there were no similar studies related to coronavirus disease, the calculations were based on the assumption that the probability of having good knowledge on and positive attitude towards preventive measures against coronavirus disease was $50.0 \%$ [10], at 95\% confidence interval, limit of precision of 5\%, with a design effect of 1.0 , the calculated sample size was 384 participants. Accordingly, the survey portal was closed, and interviews stopped at the end of the day when the number of participants exceeded the sample size, i.e. at the end of the 7 th day. 


\section{Statistical Analysis}

Descriptive statistical methods were used to summarize data on socio-demographic characteristics and medical history and responses to questions concerning knowledge, perceptions and attitude towards COVID-19. Data were summarized as frequencies (n) and percentages (\%) for categorical variables.

Knowledge concerning COVID-19 was assessed by answering 23 multiple-choice questions followed by the calculation of a total cumulative knowledge score for each participant. Questions were given one point for correct response and zero point for unanswered questions or incorrect answers. The maximum score was 23 , and the minimum was 0 .

Student's $t$ and ANOVA tests were used to determine the relation between mean knowledge score and socio-demographic variables. In the case of a significant ANOVA test, post hoc analysis (LSD) was performed for multiple comparisons between each two categories. All data analyses were performed using Statistical Package for the Social Sciences (SPSS) software, version 22. A value of $\mathrm{P}<0.05$ was considered statistically significant.

\section{Ethical Considerations}

This study was approved by the Ethics Committee of Alexandria University. Respondent's anonymity and confidentiality were ensured. The submission of the answered survey was considered as consent to participate in the study.

\section{Results}

Five hundred and fifty-nine persons from 23 governorates completed the survey. Table 1 shows the socio-demographic characteristics of the studied participants. Nearly two thirds $(62.3 \%)$ were females. Around half the participants (48.1\%) aged 18 to less than 30 years, one-quarter of them (26.8\%) aged between 30 to 40 years, whereas only $4.1 \%$ aged 60 years and above. Most of the participants $(79.2 \%)$ resided in urban areas. More than half $(52.2 \%)$ were university graduates, $17.7 \%$ had higher studies, and $25.2 \%$ had preparatory or high school education. Only $2.1 \%$ and $2.7 \%$ respectively had primary school education or could just read and write. The monthly income of a large proportion of the participants (44\%) ranged from 2000 to 5000 Egyptian pounds. Supplementary Table 1 demonstrates that $27.0 \%$ of the participants had a history of one or more chronic diseases. Moreover, $15.4 \%$ were smokers, with $4.7 \%$ of them smoking water pipes.

All participants claimed that they had heard about COVID-19. The most commonly stated sources of
Table 1 Socio-demographic characteristics of the participants $(\mathrm{n}=559)$

\begin{tabular}{|c|c|c|}
\hline Socio-demographic characteristics & No & $\%$ \\
\hline \multicolumn{3}{|l|}{ Sex } \\
\hline Male & 211 & 37.7 \\
\hline Female & 348 & 62.3 \\
\hline \multicolumn{3}{|l|}{ Age (years) } \\
\hline $18-<30$ & 269 & 48.1 \\
\hline $30-<40$ & 150 & 26.8 \\
\hline $40-<50$ & 68 & 12.2 \\
\hline $50-<60$ & 49 & 8.8 \\
\hline$\geq 60$ & 23 & 4.1 \\
\hline \multicolumn{3}{|l|}{ Area of residence } \\
\hline Urban & 443 & 79.2 \\
\hline Rural & 116 & 20.8 \\
\hline \multicolumn{3}{|l|}{ Governorate } \\
\hline Ismailia & 122 & 21.8 \\
\hline Alexandria & 113 & 20.2 \\
\hline Cairo & 95 & 17.0 \\
\hline Beheira & 77 & 13.8 \\
\hline Giza & 28 & 5.0 \\
\hline Dakahlia & 20 & 3.6 \\
\hline Others $^{\mathrm{a}}$ & 104 & 18.6 \\
\hline \multicolumn{3}{|l|}{ Highest level of education } \\
\hline Read and write & 15 & 2.7 \\
\hline Primary school & 12 & 2.1 \\
\hline Preparatory/high school & 141 & 25.2 \\
\hline University & 292 & 52.2 \\
\hline Higher studies & 99 & 17.7 \\
\hline \multicolumn{3}{|l|}{ Monthly income (LE) } \\
\hline$<2000$ & 79 & 14.1 \\
\hline $2000-<5000$ & 246 & 44.0 \\
\hline $5000-<8000$ & 89 & 15.9 \\
\hline $8000-<10,000$ & 44 & 7.9 \\
\hline$\geq 10,000$ & 101 & 18.1 \\
\hline
\end{tabular}

${ }^{a}$ Others include Sharkia, Port Said, Kafr El Sheikh, Minia, Gharbia, Qalioubya, BeniSuef, Menoufia, Suez, Assuit, Fayoum, Luxor, Aswan, Damietta, Sohag, Qena and Red Sea

knowledge were social media (66.9\%), the internet (58.3\%) followed by $\mathrm{TV} /$ satellite channels (52.6\%). Other sources included friends or family members $(38.1 \%)$, medical personnel (35.4\%) and newspapers (6.3\%) (Supplementary Table 2).

Results of knowledge assessment of the participants regarding ways of spread, common symptoms and measures to prevent the spread of COVID-19 are shown in Table 2. The total knowledge score ranged from 7 to 22 , with a mean of $16.39 \pm 2.63$.

Eighty-six percent of participants thought that the disease is dangerous, and a similar percentage was concerned about the possibility that they or their family members could 
Table 2 Knowledge about COVID-19 among the participants $(\mathrm{n}=559)$

\begin{tabular}{|c|c|c|c|c|c|c|}
\hline \multirow[t]{2}{*}{ Knowledge items } & \multicolumn{2}{|l|}{ Yes } & \multicolumn{2}{|l|}{ No } & \multicolumn{2}{|c|}{ Not sure } \\
\hline & No & $\%$ & No & $\%$ & No & $\%$ \\
\hline \multicolumn{7}{|l|}{ COVID-19 spreads by } \\
\hline 1. Droplets of affected person (with cough or expiration) & $536^{*}$ & 95.9 & 13 & 2.3 & 10 & 1.8 \\
\hline 2. Surfaces touched by affected person & $531 *$ & 95.0 & 10 & 1.8 & 18 & 3.2 \\
\hline 3. Touching coins and banknotes & 488 & 87.3 & $29^{*}$ & 5.2 & 42 & 7.5 \\
\hline 4. Dealing with pets & 175 & 31.3 & $216^{*}$ & 38.6 & 168 & 30.1 \\
\hline 5. Stool (e.g. in public toilets) & 174 & 31.1 & $168 *$ & 30.1 & 217 & 38.8 \\
\hline 6. Goods imported from China & 189 & 33.8 & $200 *$ & 35.8 & 170 & 30.4 \\
\hline 7. The disease could be transmitted from asymptomatic person & $457 *$ & 81.8 & 47 & 8.4 & 55 & 9.8 \\
\hline \multicolumn{7}{|l|}{ Common symptoms include } \\
\hline 8. Fever & $529^{*}$ & 94.6 & 8 & 1.4 & 22 & 3.9 \\
\hline 9. Dry cough & $543^{*}$ & 97.1 & 7 & 1.3 & 9 & 1.6 \\
\hline 10. Body aches & $487 *$ & 87.1 & 23 & 4.1 & 49 & 8.8 \\
\hline 11. Difficulty in breathing & $543 *$ & 97.1 & 4 & 0.7 & 12 & 2.1 \\
\hline 12. Vomiting & 129 & 23.1 & $231^{*}$ & 41.3 & 199 & 35.6 \\
\hline 13. The virus may be more dangerous for the elderly & $551^{*}$ & 98.6 & 2 & 0.4 & 6 & 1.1 \\
\hline 14. The virus may be more dangerous in patients with chronic diseases & $537^{*}$ & 96.1 & 5 & 0.9 & 17 & 3.0 \\
\hline \multicolumn{7}{|l|}{ Measures to prevent spread of the disease include } \\
\hline 15. Proper hand wash & $557 *$ & 99.6 & 1 & 0.2 & 1 & 0.2 \\
\hline $\begin{array}{l}\text { 16. Maintaining an appropriate distance between yourself and anyone with } \\
\text { symptoms }\end{array}$ & $554 *$ & 99.1 & 3 & 0.5 & 2 & 0.4 \\
\hline 17. Avoiding touching eyes, nose and mouth & $543 *$ & 97.1 & 6 & 1.1 & 10 & 1.8 \\
\hline 18. Putting on facemasks in public places & 427 & 76.4 & $59^{*}$ & 10.6 & 73 & 13.1 \\
\hline 19. Taking antibiotics & 74 & 13.2 & $380^{*}$ & 68.0 & 105 & 18.8 \\
\hline 20. Eating garlic & 185 & 33.1 & $223^{*}$ & 39.9 & 151 & 27.0 \\
\hline 21. An effective vaccine against the virus is currently available & 12 & 2.1 & $459^{*}$ & 82.1 & 88 & 15.7 \\
\hline 22. An effective treatment against the virus is currently available & 30 & 5.4 & $426^{*}$ & 76.2 & 103 & 18.4 \\
\hline 23. Antibiotics can treat the disease & 39 & 7.0 & $402 *$ & 71.9 & 118 & 21.1 \\
\hline \multicolumn{7}{|l|}{ Total score } \\
\hline Min-max & \multicolumn{6}{|l|}{$7-22$} \\
\hline Mean \pm SD & \multicolumn{6}{|c|}{$16.39 \pm 2.63$} \\
\hline
\end{tabular}

*Correct answer

Table 3 Perceptions of the participants about COVID-19 $(n=559)$

\begin{tabular}{|c|c|c|c|c|c|c|}
\hline \multirow[t]{2}{*}{ Perceptions items } & \multicolumn{2}{|l|}{ Yes } & \multicolumn{2}{|l|}{ No } & \multicolumn{2}{|c|}{ Not sure } \\
\hline & No & $\%$ & No & $\%$ & No & $\%$ \\
\hline 1. I think that this disease is dangerous & 481 & 86.0 & 46 & 8.2 & 32 & 5.7 \\
\hline $\begin{array}{l}\text { 2. I am concerned about the possibility that I or another family } \\
\text { member can get infected with this virus }\end{array}$ & 486 & 86.9 & 58 & 10.4 & 15 & 2.7 \\
\hline $\begin{array}{l}\text { 3. Infection with the virus is associated with stigma (for example: } \\
\text { the infected persons feel ashamed because people are afraid of and } \\
\text { avoid them) }\end{array}$ & 127 & 22.7 & 397 & 71.0 & 35 & 6.3 \\
\hline 4. I think the media coverage about this disease is exaggerated & 94 & 16.8 & 424 & 75.8 & 41 & 7.3 \\
\hline 5. I think this virus was initially designed as a biological weapon & 150 & 26.8 & 180 & 32.2 & 229 & 41.0 \\
\hline
\end{tabular}


get infected with the virus. More than two fifths (22.7\%) believed that infection with the virus is associated with stigma, and $16.8 \%$ thought that the media coverage about this disease is exaggerated. More than a quarter (26.8\%) thought that this virus was initially designed as a biological weapon (Table 3).

The attitude of the participants towards the preventive measures to limit the spread of COVID-19 and their responses are presented in Table 4. Generally speaking, the majority of the participants had a positive attitude towards different items of the inquired preventive measures.

The relation between socio-demographic characteristics and knowledge about COVID-19 is demonstrated in Table 5. Almost similar knowledge mean scores were observed for male and female participants $(16.27 \pm 2.63$ and $16.46 \pm 2.62$ respectively) with no statistically significant difference. On the other hand, there were statistically significant differences between knowledge mean scores of different age groups $(\mathrm{p}<0.001)$, where significantly lower knowledge mean scores were obtained for participants aged 50 to less than 60 and those $\geq 60$ years $(14.88 \pm 2.45$ and $15.26 \pm 3.05$ respectively) compared to the younger age groups. Also, the urban areas residents had a significantly higher mean score among $(16.66 \pm 2.53)$ compared to rural areas residents $(15.35 \pm 2.74) ;(\mathrm{p}<0.001)$. The knowledge mean scores were significantly related to the level of education as well as to the monthly income $(p<0.001)$. Participants with university or higher education had significantly higher knowledge mean scores compared to those with lower levels of education. Similarly, participants with monthly incomes of less than 5000 Egyptian pounds had significantly lower knowledge mean scores compared to participants with higher incomes.

\section{Discussion}

COVID-19 disease was first identified during the outbreak of severe acute respiratory syndrome in Wuhan, China, in December 2019 [11]. On the 11th of March 2020, the World Health Organization (WHO) characterized the disease as the first pandemic caused by a coronavirus [12]. The disease had spread in more than 200 countries with a mortality rate of about $5.7 \%$ [13].

Egypt is one of the biggest countries in the Arab region, Africa and the Middle East. With more than 100 million citizens, Egypt is among the most populous countries in Africa [14]. This high number of citizens could be associated with a great risk of spread and mortality, especially among old persons and those with chronic diseases. Global efforts have been exerted to prevent the spreading of the virus. These efforts include political efforts by the governments, together with personal attitude and behaviors, which depend on the awareness of the general public about the disease. Here we present the results of a survey about the knowledge perceptions, and attitudes of the Egyptian public towards the COVD-19 disease.

\section{Knowledge About the Spread, Prevention and Treatment of the Disease}

In general, participants in our survey had good general knowledge about the disease, its methods of spread, and prevention. According to the information provided by the WHO and the Egyptian Ministry of Health (MOH) to the public, we divided the symptoms of the disease into common and less common ones, and asked participants about these symptoms, which denoted a good level of knowledge about this point.

Novel channels including, social media platforms, and the internet represented the most important sources of information, at the expense of more traditional media platforms; namely: newspapers. Facebook is the main social media platform in Egypt, and users of this platform increased from 33 million users in 2016 to more than 40 million in 2019 [15, 16]. Interestingly, about $75 \%$ of our participants were in the age groups between 18 and 40 years, which represent more than 75\% of Facebook users in Egypt [15, 16]. MOH started using different means of communication, including television and street ads, as well as mobile messages, to educate the public about the disease. Recently, $\mathrm{MOH}$ also started using sponsored ads on Facebook, which denotes awareness of policymakers about the importance of this platform.

Although these platforms provide an easy and accessible ways of getting information, they can also be a source of misinformation. Fake news on Facebook about potential drugs, including hydroxychloroquine that may be used to treat COVID-19 motivated a lot of people to buy these drugs without medical supervision, causing shortage of these drugs for patients who are in real need for them [17]. Caution about the use of these platforms must be present, to avoid the spread of fabricated data and rumors.

In our participants, the mean knowledge score was significantly lower among older participants, those living in rural areas, with lower educational and monthly income levels. These results are similar to the results of a Chinese study, in which participants with high socioeconomic status were knowledgeable, and followed appropriate practices to prevent the spread of COVID-19 [8]. Our results are important since they may denote that more efforts should be exerted to deliver the message to these categories, which may have technical and/or financial difficulties getting access to the novel communication platforms.

\section{Perceptions About the Disease}

When we asked our participants about their perceptions regarding infection with the virus, most participants believed 


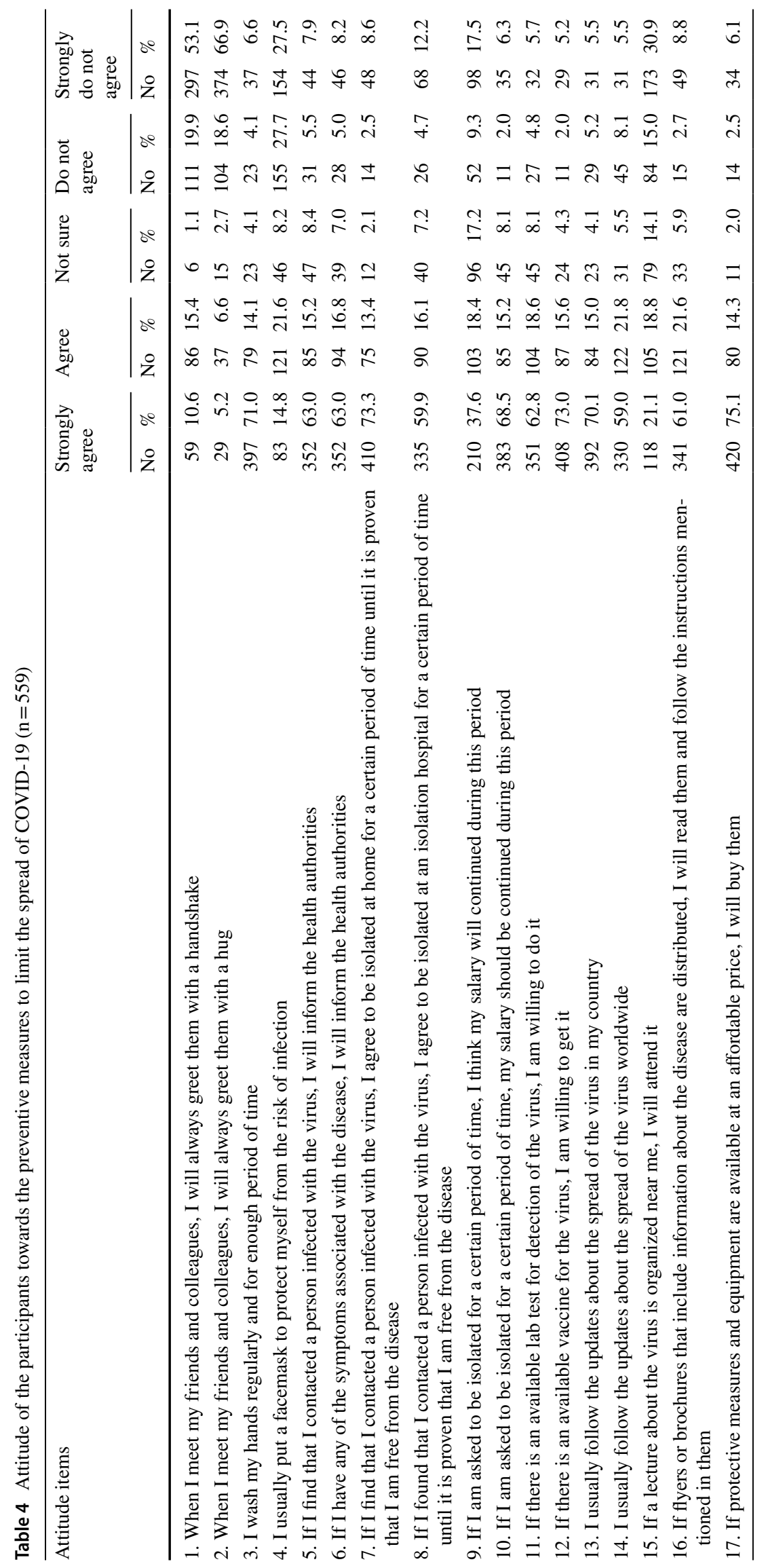




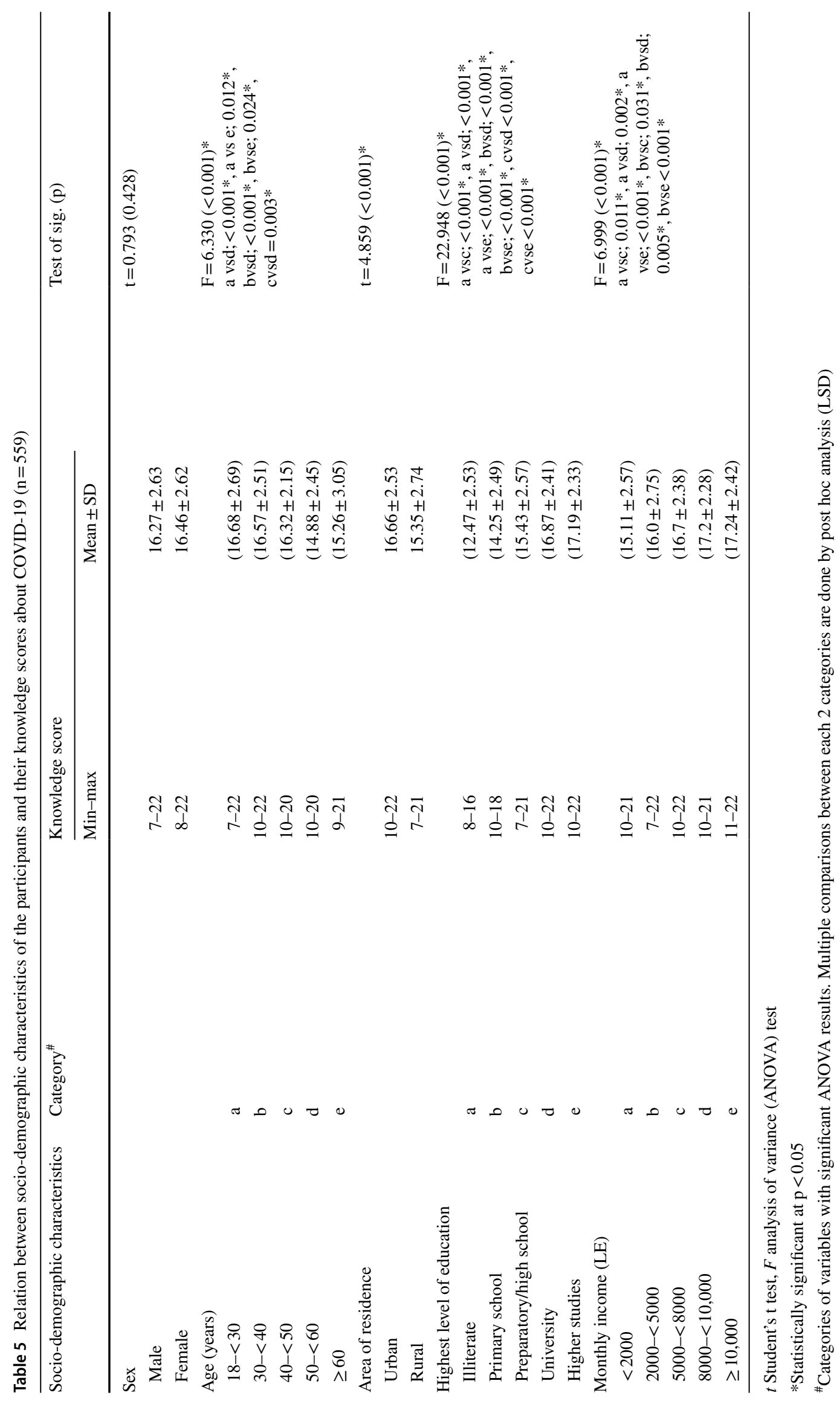


that it represents a life-threatening danger, and were concerned about the potential risk of infection of any member of their families. Twenty-seven percent of our participants had chronic diseases, and a great majority of participants believed that the disease is more dangerous for the elderly, and those with chronic diseases. This has been proven from multiple studies published about the disease in China [18, 19]. Again this reflects the effectiveness of the message provided by the different media platforms, which was confirmed by the negative assumptions that that media is exaggerating the risk ( $16.8 \%$ only thought that media outlets exaggerate the danger of the disease).

A little over a quarter of participants thought that the virus started as a biological weapon. This limited number is interesting since it also reflects the growing awareness of the public. A rumor about research that claims that the SARSCoV-2 was created in laboratories has spread through social media in Egypt. The research, actually a preprint, was later withdrawn by authors over peers' criticism [20]. An article published in Nature Medicine concluded that the virus is not purposefully manipulated or created in laboratories [21]. Again, this sheds light on the cons of using social media platforms as a communication tool.

About 23\% of participants thought the infection of the virus is associated with stigma. Although the number is limited, we think that it has significance, since it may lead to underreporting of cases, which may cause rapid spread of the disease. The most common example of patient stigma in Egypt, even among healthcare groups, is the one associated with infection with HIV. A cross-sectional survey conducted at one of the Egyptian university hospitals showed that healthcare workers had high levels of stigma towards people living with HIV, and called for stigma reduction programs in Egyptian hospitals [22]. We believe that the social stigma associated with COVID-19 is much different from that of HIV, since the latter involves negative beliefs, feelings and attitudes towards those infected with the virus. On the contrary, the stigma of COVID-19 does not involve these negative feelings towards patients. Stigma towards COVID-19 is due to the fear of its mortality and high communicability, thus can be resolved through proper education and transparency of healthcare policies.

\section{Attitudes Towards the Preventive Measures of COVID-19}

In our study, participants showed a positive general attitude towards measures that can be followed to prevent the transmission of the disease. They believed in the value of hand washing and limited personal contact. While about threequarters of participants believed that putting a face mask can protect from infection, only about $35 \%$ were willing to do this. Almost all participants in a Chinese study used to put face masks when they go out during the current pandemic [8]. Recently, the CDC recommended putting cloth face coverings for the public, especially in areas where there is significant community-based transmission [23]. On the other hand, WHO recommends using face masks only if a person has respiratory symptoms or caring for another person with symptoms [24]. There is no consensus about the rationale of use of face masks in public places to prevent the spread of COVID-19 [25]. It is recommended that guidelines about this issue be developed by governments and local public health agencies to control the unnecessary use of surgical masks, which are consumed rapidly during the current pandemic time.

About three-quarters of participants were willing to be isolated at home, and a lower proportion (59.9\%) was willing to stay in the hospital if they contacted a case infected with the virus. In order to minimize the crowd and slow the spread, the government of Egypt enforced a nighttime curfew for 2 weeks starting from the last week of March 2020. The decision included the closure of all restaurants and cafes for the same period of time [26]. Water pipe smoking is growing in Egypt [27], and among our participants, about $5 \%$ used to smoke water pipes, which may be a source of transmission of COVID-19 through the sharing of mouth pieces and hoses [28]. Accordingly, the decision of the government may help prevent this source of transmission of infection.

While the health burden of COVID-19 is important, the economic burden should not be overlooked. We recognized a difference between the number of participants who thought that their salary will be continued if they are isolated (37.6\%), and those who believed it should be continued $(68.5 \%)$. We think that this difference has significance since it reflects the financial fears of participants, which could also be reflected in the form of underreporting of cases. These concerns should be addressed with openness and transparency. The Egyptian president announced that 100 billion Egyptian pounds ( $\$ 6.38$ billion) had been allocated to fight the corona virus [29]. We think that a part of this fund should be directed to support the most affected groups from the economic sequel of the disease.

The majority of our participants was willing to get tested to detect the virus, and was willing to get the vaccine once it is available. We think that some degree of governmental control should be present over the distribution of any approved vaccine or treatment, which should provide priority for the vulnerable groups.

The development of vaccine and treatment for COVID19 raises many ethical questions. At the top of these questions come two basic questions: Who will get access to the vaccine and/or treatment? And how much will governments and individuals have to pay for them? The avian influenza case of Indonesia, where the country supplied the samples 
but didn't have free access to the developed vaccine, clearly demonstrated this problem, and showed the imbalance between developed and developing countries in this aspect [30]. Interestingly, the Egyptian government had a very successful model for drug delivery during 100 Million Healthy Lives program to eliminate hepatitis C in Egypt [31]. First, Egyptian companies got permission to formulate several generic direct-acting antivirals against hepatitis $\mathrm{C}$ at a very affordable price through an exemption under the World Trade Organization Agreement on Trade-Related Aspects of Intellectual Property Rights [32]. Second, the successful treatment program was under the umbrella of the government, which controlled the process of treatment and distribution of the drugs [31]. Finally, the program also included screening for diabetes, hypertension, as well as obesity. So, the Egyptian government now has a database of vulnerable groups among about 50 million adult Egyptian [31, 32]. This database can be very useful if a new vaccine or treatment is approved for COVID-19.

\section{Conclusions and Recommendations}

In general, Egyptians participating in our survey had good knowledge about COVID-19, and a positive attitude towards using protective measures, which is important to limit the spread of the disease. This knowledge is mainly acquired through social media platforms and the internet, which has pros and cons. However, knowledge was lower among older, rural, less educated, and lower income groups. This may necessitate more efforts or using different tools to communicate with these groups. Although the government has taken major steps to limit the spread of the disease, more effort is needed to support the most affected groups from the economic sequel of the disease. If a vaccine or a treatment is approved for the disease, we recommend that it should be available for developing countries for affordable prices and government control over the use of the vaccine and/or treatment to preserve the rights of the vulnerable and needy groups.

\section{Limitations of the Study}

The distribution of the survey through the internet allowed only those who can read and have internet access to participate. This represents a major limitation of this study.

Funding This research did not receive any specific grant from funding agencies in the public, commercial, or not-for-profit sectors.

\section{Compliance with Ethical Standards}

Conflict of interest The authors declare that they have no conflict of interest.

\section{References}

1. Shigemura, J., Ursano, R. J., Morganstein, J. C., et al. (2020). Public responses to the novel 2019 coronavirus (2019-nCoV) in Japan: Mental health consequences and target populations. Psychiatry and Clinical Neurosciences. https://doi.org/10.1111/ pcn. 12988.

2. Li, Y. C., Bai, W. Z., \& Hashikawa, T. (2020). The neuroinvasive potential of SARS-CoV2 may play a role in the respiratory failure of COVID-19 patients. Journal of Medical Virology. https://doi. org/10.1002/jmv.25728.

3. Cascella, M., Rajnik, M., Cuomo, A., et al. (2020). Features, Evaluation and Treatment Coronavirus (COVID-19), in StatPearls. Treasure Island, FL: StatPearls Publishing LLC.

4. Huang, C., Wang, Y., Li, X., et al. (2020). Clinical features of patients infected with 2019 novel coronavirus in Wuhan China. The Lancet, 395(10223), 497-506.

5. Guo, Y. R., Cao, Q. D., Hong, Z. S., et al. (2020). The origin, transmission and clinical therapies on coronavirus disease 2019 (COVID-19) outbreak - an update on the status. Military Medical Research, 7(1), 11.

6. Li, J. Y., You, Z., Wang, Q., et al. (2020). The epidemic of 2019-novel-coronavirus (2019-nCoV) pneumonia and insights for emerging infectious diseases in the future. Microbes and Infection, 22(2), 80-85.

7. Egypitan PM: Egypt's coronavirus figures still within range. Retrieved April 17, 2020 4, 2020, from https://www.egypttoday .com/Article/2/83291/PM-Egypt\%E2\%80\%99s-coronavirus-figur es-still-within-range.

8. Zhong, B. L., Luo, W., Li, H. M., et al. (2020). Knowledge, attitudes, and practices towards COVID-19 among Chinese residents during the rapid rise period of the COVID-19 outbreak: A quick online cross-sectional survey. International Journal of Biological Sciences, 16(10), 1745-1752.

9. Hung, L. S. (2003). The SARS epidemic in Hong Kong: What lessons have we learned? Journal of the Royal Society of Medicine, 96(8), 374-378.

10. Lemeshow, S., Hosmer, D. W., Klar, J., et al. (1990). World Health Organization. Adequacy of sample size in health studies. Chichester: Wiley. Retrieved April 4, 2020, from https://apps.who.int/ iris/handle/10665/41607.

11. The World Heath Organization Q\&A on coronaviruses (COVID19) (2020). Retrieved April 4, 2020, from https://www.who.int/ news-room/q-a-detail/q-a-coronaviruses.

12. WHO Director-General's opening remarks at the media briefing on COVID-19 11 March 2020. Retrieved April 4, 2020, from https ://www.who.int/dg/speeches/detail/who-director-general-s-openi ng-remarks-at-the-media-briefing-on-covid-19-11-march-2020).

13. Baud, D., Qi, X., Nielsen-Saines, K., et al. (2020). Real estimates of mortality following COVID-19 infection. The Lancet Infectious Diseases. https://doi.org/10.1016/S1473-3099(20)30195-X.

14. The Central Agency for Public Mobilization and Statistics Website (2020). Retrieved April 4, 2020, from https://www.capmas.gov. eg/Pages/populationClock.aspx\#

15. Abdelhafiz, A. S., Fouda, M. A., El-Jaafary, S. I., et al. (2017). Targeting future customers: An introductory biobanking course for undergraduate students of life sciences. Biopreservation 
and Biobanking, 15(4), 350-359. https://doi.org/10.1089/ bio.2016.0111.

16. Facebook users in Egypt in Febraury (2019). Retrieved April 4, 2020, from https://napoleoncat.com/stats/facebook-users-inegypt/2019/02.

17. The Medical Syndicate is investigating with a doctor for prescribing medications to treat Covid-19 (2020). Retrieved April 4, 2020, from https://bit.ly/2x34wIH.

18. Li, L. Q., Huang, T., Wang, Y. Q., et al. (2020). Novel coronavirus patients' clinical characteristics, discharge rate, and fatality rate of meta-analysis. Journal of Medical Virology, 2020, 1-7. https://doi.org/10.1002/jmv.25757.

19. Liang, W., Guan, W., Chen, R., et al. (2020). Cancer patients in SARS-CoV-2 infection: A nationwide analysis in China. The Lancet Oncology, 21(3), 335-337. https://doi.org/10.1016/ S1470-2045(20)30096-6.

20. A preprint: Uncanny similarity of unique inserts in the 2019-nCoV spike protein to HIV-1 gp120 and Gag (2020). Retrieved April 4, 2020, from https://www.biorxiv.org/conte $\mathrm{nt} / 10.1101 / 2020.01 .30 .927871 \mathrm{v} 2$.

21. Andersen, K. G., Rambaut, A., Lipkin, W. I., et al. (2020). (2020) The proximal origin of SARS-CoV-2. Nature Medicine. https://doi.org/10.1038/s41591-020-0820-9.

22. Kabbash, I. A., Abo Ali, E. A., Elgendy, M. M., et al. (2018). HIV/AIDS-related stigma and discrimination among health care workers at Tanta University Hospitals Egypt. Environmental Science and Pollution Research, 25, 30755-30762. https://doi. org/10.1007/s11356-016-7848-x.

23. Recommendation Regarding the Use of Cloth Face Coverings, Especially in Areas of Significant Community-Based Transmission (2020). Retrieved April 4, 2020, from https://www.cdc.gov/ coronavirus/2019-ncov/prevent-getting-sick/cloth-face-cover .html.

24. Coronavirus disease (COVID-19) advice for the public: When and how to use masks (2020). Retrieved April 4, 2020, from https://www.who.int/emergencies/diseases/novel-coronaviru s-2019/advice-for-public/when-and-how-to-use-masks.
25. Feng, S., Shen, C., Xia, N., et al. (2020). Rational use of face masks in the COVID-19 pandemic. The Lancet Respiratory Medicine. https://doi.org/10.1016/S2213-2600(20)30134-X.

26. Egyptian government's anti-virus plan met with mixed reactions (2020). Retrieved April 4, 2020, from https://www.almonitor.com/pulse/originals/2020/03/egypt-coronavirus-curfe w-sisi-measures-protests.html.

27. Mostafa, A., Mohammed, H. T., Hussein, W. M., et al. (2018). Plain packaging of waterpipe tobacco? A qualitative analysis exploring waterpipe smokers' and non-smokers' responses to enhanced versus existing pictorial health warnings in Egypt. British Medical Journal Open, 8(10), e023496. https://doi. org/10.1136/bmjopen-2018-023496.

28. Q\&A on smoking and COVID-19 (2020). Retrieved April 4, 2020, from https://www.who.int/newsroom/q-a-detail/q-a-onsmoking-and-covid-19.

29. Egypt shuts schools, universities for two weeks as virus cases increase (2020). Retrieved April 4, 2020, from https://www. reuters.com/article/us-health-coronavirus-egypt/egypt-shuts -schools-universities-for-two-weeks-as-virus-cases-increaseidUSKBN2110SH.

30. Sedyaningsih, E. R., Isfandari, S., Soendoro, T., et al. (2008). Towards mutual trust, transparency and equity in virus sharing mechanism: The Avian Influenza case of Indonesia. Annals of the Academy of Medicine (Singapore), 37(6), 482-488.

31. Waked, I., Esmat, G., Elsharkawy, A., et al. (2020). Screening and treatemnt program to eliminate hepatitis $\mathrm{C}$ in Egypt. New England Journal of Medicine, 382(12), 1166-1174. https://doi. org/10.1056/NEJMsr1912628.

32. Haseltine, W. A. (2020). (2020) Universal disease screening and treatment- the Egyptian example. New England Journal of Medicine, 382(12), 1081-1083. https://doi.org/10.1056/NEJMp19158 18.

Publisher's Note Springer Nature remains neutral with regard to jurisdictional claims in published maps and institutional affiliations. 